\title{
O GINÁSIO CRISTO REI DE UBERLÂNDIA, MG (1944-1956), UMA ESCOLA PROFISSIONAL
}

\author{
Sandra Ferreira de Oliveira ${ }^{1}$ \\ sandryoliveira@gmail.com. \\ José Carlos Souza Araujo ${ }^{2}$ \\ jcaraujo@ufu.br \\ Universidade Federal de Uberlândia
}

\section{RESUMO:}

O objeto deste é a história da educação do Ginásio Profissional Cristo Rei (1944-1956) de Uberlândia, MG, focalizado como espaço de formação dos alunos pobres. Nesse sentido, busca-se resgatar sua história, seu processo de criação e instalação, sua cotidianidade institucional em vista da educação oferecida por essa entidade. Para a estruturação do trabalho serão privilegiados os documentos da própria instituição, a imprensa local, bem como materiais oriundos de acervos de ex-alunos. A metodologia de investigação dos aspectos envolvidos na história do Ginásio Cristo Rei, a movimentação entre o embasamento teórico e as fontes permitiram a (re) construção do período histórico pesquisado. Optou-se pela análise documental, bem como da história oral como técnica de pesquisa com o objetivo de elucidar questões específicas a respeito da temática do ponto de vista local. Diante da perspectiva de modernização da cidade de Uberlândia, essa escola ganhou um espaço primordial nesse processo de desenvolvimento, passando a ser vista como uma das vias de acesso para o progresso do mesmo, no intento de criar condições por meio do estudo para uma nova forma de ascensão social. Nessa configuração contribuiu com o projeto de progresso da cidade, na tentativa de eliminar das áreas públicas os sinais de desordem, traduzidas pela pobreza infantil.

Palavras-chave: Instituição Escolar, Escola Salesiana, Ginásio, Infância Pobre, Escola Profissional, Uberlândia, Triângulo Mineiro.

\section{THE "UBERLÂNDIA, MG, CRISTO REI GYMNASIUM (1944-1956) PROFESSIONAL SCHOOL}

\begin{abstract}
:
The object of this is the history of education of Christ the King Professional Gym (19441956) in Uberlândia, MG, targeted as an area of training for poor students. In this sense, it seeks to redeem its history, its process of creation and installation, your everyday institutional view of education offered by that entity. For the structuring of the work will be privileged documents of the institution, the local press as well as materials from the collections of former students. The methodology of investigation of aspects involved in the history of Christ the King Gym, moving between the theoretical and the sources allowed the (re) construction of the historical period studied. We opted for the documentary analysis and oral history as a research aimed at elucidating more specific about the subject. Faced with the prospect of modernizing the city of Uberlandia, this school has won a prime space in the process of development began to be seen as one of access routes to the same progress with the intent of creating conditions by studying a new form of social mobility, this configuration has contributed to the project of progress of the city in an attempt to eliminate the signs of the public areas of disorder, translated by child poverty.
\end{abstract}


Keywords: Institution School, Salesian School, Gymnasium, Children Poor, Professional School, Uberlandia, Minas Triangle.

Por se tratar de um estudo sobre uma instituição escolar, é pertinente conceituá-la: "uma unidade escolar é uma instituição como também o conjunto de todas as escolas componentes da rede de ensino de que se faz parte" (BARRETO, 1986). Ou: "o conceito de instituição é um conceito ambíguo e mais complexo que se possa parecer. Utilizamos instituição para indicar uma única escola e também para indicar um sistema escolar". (RAGAZZANI, 1999, p. 26).

Magalhães (1998), em seu estudo sobre instituições escolares, apreende que a história da educação procura reconstruir e representar fenômenos educacionais de acordo com uma perspectiva historiográfica e, nesse universo educacional, se encontram as instituições educativas que possuem uma cultura pedagógica permeada por práticas, idéias, desejos e interesses diversos, de acordo com suas funções, seus membros e os conteúdos que se ministram.

Nesse sentido, a problematização da instituição educativa em seu contexto sóciocultural, as investigações e, ainda, a (re) construção das representações simbólicas das práticas educativas vão conceder à escola uma identidade histórica.

Assim, para abranger a realidade histórica de uma instituição, Justino Magalhães (1998), em seu estudo sobre instituições escolares, salienta a relevância da memória: “[...] uma história construída da(s) memória (s) para o arquivo e do arquivo para a memória" (p. 61). O resgate da memória de uma instituição escolar é de fundamental importância como suporte para a análise da história da educação brasileira.

A pesquisa historiográfica na área de instituições escolares parece enfatizar o papel dos atores envolvidos no processo de desenvolvimento educativo que ocorre nas escolas. Magalhães (1998) entende:

Compreender a existência histórica de uma instituição educativa é, sem deixar de integrá-la à realidade mais ampla, que é o sistema educativo, contextualizá-la implicando-a no quadro de evolução de uma comunidade e de uma região, é, por fim, sistematizar e (re) escrever-lhe o itinerário de vida na sua multimensionalidade, conferindo-lhe um sentido histórico. (MAGALHÃES, 1998, p. 2)

A contextualização espacial e temporal de uma instituição a ser investigada permite a apreensão de uma realidade social mais ampla. Nesse sentido, a escola está inserida na sociedade, produzindo e reproduzindo os ideais sociais; daí a necessidade de se fazer uma história interpretativa das instituições escolares, pois "as escolas apresentam-se como locais que portam um arsenal de fontes, e de informações fundamentais para a formulação 
de interpretações sobre elas próprias e, sobretudo, sobre a História da Educação Brasileira" (GATTI JR, 2000, p. 113).

Nessa perspectiva, segundo Justino Magalhães (1999), a análise de uma instituição escolar deve compreender a identidade cultural e educacional da entidade, considerando seu tempo e espaço, suas mudanças e permanências e suas relações entre o local e o regional e entre o geral e o nacional.

[...] a instituição educativa se constitui no plano histórico, como no plano pedagógico, uma totalidade em constituição e organização, investindo-se de uma identidade. As instituições educativas têm uma estrutura física, uma estrutura administrativa, e sócio-cultural. A função básica de uma instituição objetiva-se na produção e na transmissão de cultura. (MAGALHÃES, 1999, p. 69)

A escola estabelece uma cultura própria, caracterizada por um ritualismo tanto de produção como de socialização dos conhecimentos acumulados, além da mesma constituirse com um conjunto de valores e comportamentos que têm nela sua principal propagação.

O Ginásio Cristo Rei, instalado em Uberlândia em 1944, teve uma contribuição significativa na escolarização da população uberlandense, uma vez que se inseria no contexto de modernização que o município vivenciava. Pretende-se, nesse artigo, investigar historicamente o Ginásio Profissional Cristo Rei, de modo a compreender sua constituição, em quais circunstâncias se desenvolveu, qual papel exerceu, uma vez que se parte da hipótese de que essa instituição teria a finalidade de promover educação formal e reeducação social de alunos de baixa renda, contribuindo, assim, para a realização de um projeto de progresso, o qual se pautava na higienização social da cidade de Uberlândia. Contudo, posteriormente, a Congregação Salesiana, responsável por essa instituição, assumiu outra direção, posto que seu atendimento às crianças de classes mais abastadas configurou-se a partir dos meados da década de 1950.

Para tal investigação, fez-se necessária uma reflexão sobre a formação do município de Uberlândia, no que se refere ao seu desenvolvimento e à sua urbanização; além disso, coube elaborar uma sucinta explanação sobre a Congregação Salesiana, uma vez que a escola em estudo foi um estabelecimento católico salesiano. Para tanto, as principais fontes de estudo e pesquisa encontram-se em periódicos e em jornais, bem como na documentação escolar do Ginásio Profissional Cristo Rei, além da bibliografia atinente ao objeto em apreço.

\section{Cenário econômico-social de Uberlândia, MG}

A história da cidade de Uberlândia descoberta pelos bandeirantes começou com a ocupação da região no Triangulo Mineiro e efetivou-se no início do século XIX; anteriormente, era apenas um ponto de passagem de tropeiros e mineradores, ou um entreposto. 
Figura 01 - Localização de Uberlândia no Triângulo Mineiro e da área urbana

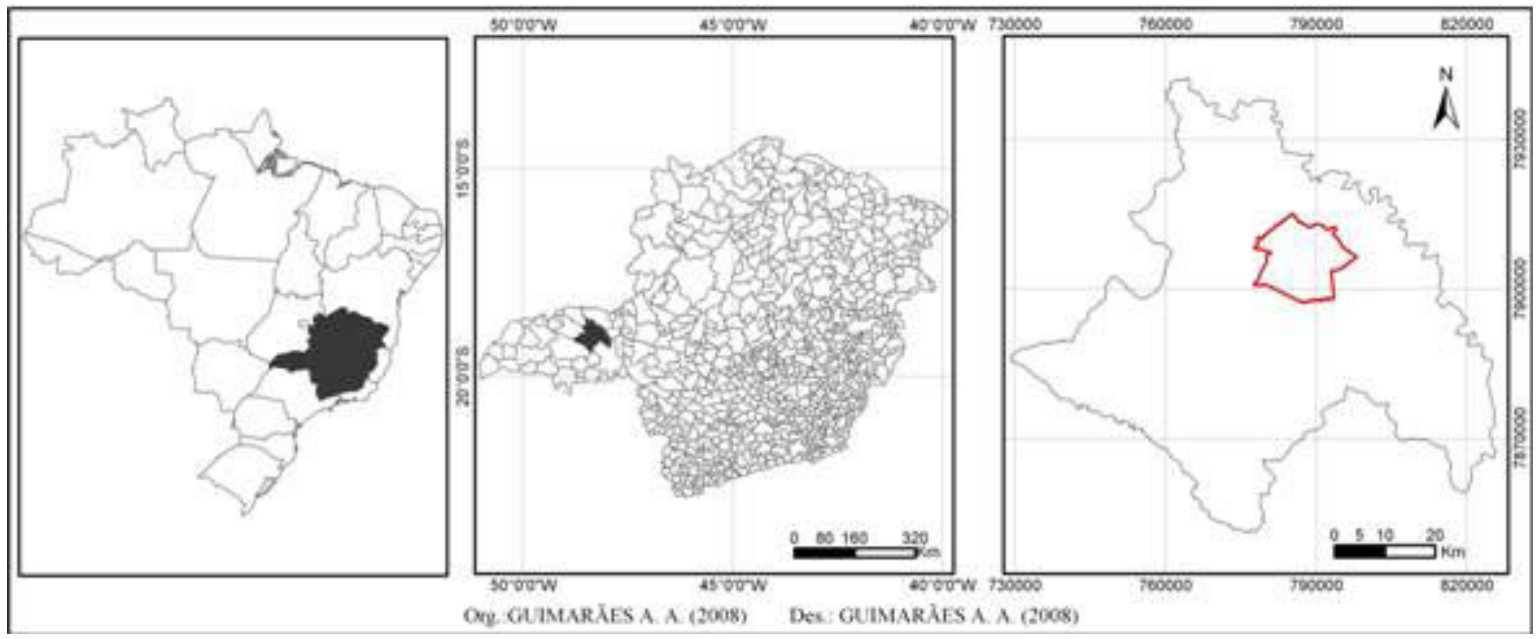

Fonte: Alves \& Filho, 2008, p.3

Esta região pertenceu à Capitania de Goiás até 1816 - e anteriormente, à Capitania de São Paulo até 1720 -, passando a pertencer à Província de Minas Gerais. No intuito de colonizar as terras situadas na região, o governo de Minas iniciou uma campanha visando intensificar a ocupação do sertão da Farinha Podre ${ }^{3}$. Nessa época, os índios Caiapós, primitivos habitantes da região, foram deslocados para as regiões de Goiás e Mato Grosso, em vista da ocupação da área pelos desbravadores. Entre estes, encontrava-se João Pereira da Rocha que, atraído pela possibilidade de ocupação e de exploraçao, constituiu uma sesmaria no início do século XIX.

Historicamente, o município de Uberabinha $^{4}$ destacou-se de outras cidades circunvizinhas por meio de construções de estradas e escolas, o que veio a favorecer o seu crescente desenvolvimento. De acordo com o memorialista local, Capri (1916):

[...] surge a cidade em uma elevação entre o rio Uberabinha, córrego São Pedro e Itajubá pela parte do oeste, sul e norte, respectivamente, pela parte leste, chega a linha férrea. Quem vem de São Paulo pela mogyanna, avista-a de uma légua de distancia, muito branca e sorridente, lá em baixo, sobresahindo pela sua altura, as torres da matriz. Dir-se-ia uma noiva esperando o seu promettido companheiro, que neste caso será o progresso. (p. 21-22)

A localização estratégica da cidade e suas condições topográficas favoráveis foram bem aproveitadas através da construção de uma estrada de rodagem, no início do século XX, pela Companhia Mineira de Auto- Aviação Intermunicipal. Com a expansão da malha de transporte, cresceu o fluxo rodoviário e ferroviário, interligando os estados de Minas Gerais, São Paulo, Goiás e Mato Grosso. Com isso, a Uberabinha de então teve adensado o seu desenvolvimento, e começou a firmar, paulatinamente, sua supremacia em relação às demais cidades da região. 
Apesar da estrutura agrária que fundamentava o município, uma vez que sua economia estava organizada em bases agrícolas, pastoris e comerciais, veiculava desde então a concepção de progresso associada à vida urbana, o que perpassava o ideário da época.

Essa concepção foi sendo engendrada a partir do crescimento urbano brasileiro, além de estar diretamente ligada ao desenvolvimento econômico do país. Esse processo de desenvolvimento foi acompanhado por intensa e acelerada urbanização "[...] hoje virtual, amanhã real. A expressão reservada à sociedade que nasce da industrialização. Estas palavras designam, portanto, a sociedade construída por esse processo e absorve a produção agrícola" (LEFEBVRE, 2008, p.13). O modelo econômico vigente evoluía para uma etapa mais eficiente da acumulação de capitais e, com isso, toda a sociedade se reestruturava aos moldes comerciais e industriais.

Desencadeou-se um processo de crescimento das aglomerações urbanas, concomitantemente ao esvaziamento demográfico das áreas rurais. A produção agrícola tornou-se um setor de caráter industrial, o que fez com que as áreas rurais ficassem submissas às exigências do capital urbano-industrial. $O$ "tecido urbano prolifera, estendese, corrói os resíduos da vida agrária” (LEFEBVRE, 2008, p.15).

Segundo Machado (1990), o controle social de cunho assistencialista, em Uberlândia, fundamentou-se, desde a década de 1920, em discursos modernos sobre a caridade pública. "Contra a pobreza que se expõe cotidianamente no espaço público, foi pensada a institucionalização da caridade que consagra a ajuda como um direito daqueles que vivem em um estado de indigência, o qual ameaça a ordem social burguesa" (MACHADO, 1990, p.112).

Essa prática se prolongou ao longo dos anos, na esperança de obter uma solução pelas autoridades municipais. No período em estudo, percebe-se uma continuidade do problema, propagado pela imprensa local, que exprimia o anseio de seus citadinos, que almejava o progresso e a modernização; sobretudo, porque essas mudanças fundamentavam a expansão das relações capitalistas. idéia:

A citação a seguir de uma matéria jornalística d'O Reporter evidencia bem essa

[...] Trata-se da vadiagem desenfreada de uma grande parte de menores desta cidade, na maioria pequenos desclassificados, sem Paes nem tutores, aos joguetes de uma permissão criminosa que os conduz pouco a pouco á nullidade moral e physica, e que os botará amanhã, fatalmente, à margem da vida como indesejáveis elementos nocivos á sociedade (UM CORRECTIVO que se impõe. O Reporter, Uberlândia, MG, 1935, p.1)

No entanto, não eram consideradas vadias somente as crianças desvalidas, como ressalta a mesma publicação:

[...] existem muitos pequenos vadios entre nós cuja posição financeira dos Paes permitte-lhes perfeitamente uma directriz segura de sua formação. No entanto viem por ahi descurados dos zelos paternaes, armazenando os maus exemplos dos tarados com quem, á força de contínuo contacto, se fazem camaradas e discípulos intransigentes. (UM CORRECTIVO que se impõe. O Reporter, Uberlândia, MG, 1935, p.1) 
Apreende-se, por conseguinte, que a problemática do menor, em Uberlândia, era perceptível na fala da elite. Segundo Machado (1990), a ausência de estrutura familiar e os defeitos da formação social concorriam para determinar o problema da infância abandonada e da delinqüência juvenil:

[...] É de lamentar a inepcia em que permanecem muitos paes, deixando seus filhos vagarem até altas horas da noite, formando bandos que praticam por toda a parte actos que somente cabe aos Paes corrigir. (FALTA-LHES EDUCAÇÃO. O Reporter, Uberlândia, MG, 1935, p.2)

Desse modo, com o crescimento das massas empobrecidas e, conseqüentemente, da mendicância e da pobreza infantil nessa cidade,

[...] a beneficência passa a se institucionalizar num dado momento histórico, formando um conjunto integrante de intenções e ações com as mesmas características já descritas. Assim, hospitais, asilos, orfanatos, por exemplos, são locais onde é praticado o bem estar, na forma de auxílio concreto ou de serviços. (SILVA, 1986, p. 119)

Colocar em prática esse discurso da moderna filantropia era uma preocupação constante da sociedade uberlandense. Assim, para tirar das ruas mendigos e crianças abandonadas, buscaram-se formas alternativas de tratamento do pobre: "assim, ao relacionar a pobreza à criminalidade, tem-se a justificativa para disciplinar e higienizar o espaço urbano, no qual vem ganhando relevância a atuação das instituições" (CARVALHO, 2007, p. 162).

Desse modo, a cidade de Uberlândia apresentou como promotoras dessa assepsia social, entidades de caráter religioso, comandadas por pessoas representativas da classe dominante. Observe-se que esses empreendimentos seriam benéficos à coletividade uberlandense, evidenciados por esse discurso local: "[...] numa casa de recolhimento dessas creanças, afastando as dos meios prejudiciais e encaminhando-as a educação sadia de estabelecimento regenerador" (PATRONATO DE MENORES, O Reporter, Uberlândia, MG, 1943, p.1).

Assim como o patronato de menor seria considerado uma instituição regeneradora dessas crianças, "tendo em vista a sua importância na formação moral e profissional destas crianças" (MACHADO, 1990, p.257), outras instituições contariam com o apoio da população da cidade. No quadro abaixo, estão relacionadas algumas instituições criadas para atender à higienização social.

Quadro 01 - Principais Instituições Assistenciais de Uberlândia, 1900-1950

\begin{tabular}{|l|c|c|c|c|}
\hline \multicolumn{1}{|c|}{ Instituição } & Datas & Responsável pela obra & Objetivos & Observações \\
\hline $\begin{array}{l}\text { Asilo Santo } \\
\text { Antonio e São } \\
\text { Vicente de Paula }\end{array}$ & 1908 & $\begin{array}{c}\text { Irmandade da Misericórdia } \\
\text { de Uberabinha/Sociedade } \\
\text { São Vicente de Paula }\end{array}$ & $\begin{array}{c}\text { Recolhimento de } \\
\text { pessoas idosas, } \\
\text { carentes e } \\
\text { abandonadas. }\end{array}$ & - \\
\hline
\end{tabular}




\begin{tabular}{|c|c|c|c|c|}
\hline $\begin{array}{l}\text { Santa Casa de } \\
\text { Misericórdia }\end{array}$ & $1917-1970$ & $\begin{array}{l}\text { Irmandade da Misericórdia } \\
\text { de Uberabinha/ Sociedade } \\
\text { São Vicente de Paula }\end{array}$ & $\begin{array}{l}\text { Atendimento médico } \\
\text { as pessoas pobres e } \\
\text { carentes }\end{array}$ & $\begin{array}{l}\text { Existência irregular até } 1940, \\
\text { quando foi assumida pela } \\
\text { Sociedade São Vicente de } \\
\text { Paula }\end{array}$ \\
\hline $\begin{array}{l}\text { Hospital regional } \\
\text { de Uberlândia }\end{array}$ & $1930-1940$ & Governo Estadual & $\begin{array}{l}\text { Atendimento médico } \\
\text { as pessoas pobres e } \\
\text { carentes }\end{array}$ & $\begin{array}{l}\text { Resultado do programa se } \\
\text { saúde do Governo Vargas }\end{array}$ \\
\hline $\begin{array}{l}\text { Dispensários } \\
\text { pobres dos } \\
\text { Uberlândia }\end{array}$ & $1934-1970$ & $\begin{array}{c}\text { Sociedade São Vicente de } \\
\text { Paula }\end{array}$ & $\begin{array}{c}\text { Retirada dos } \\
\text { mendigos da rua, } \\
\text { auxílio material, } \\
\text { controle de doenças } \\
\text { contagiosas }\end{array}$ & $\begin{array}{ll}\text { Principal alvo: } & \text { doentes } \\
\text { portadores da lepra. } & \end{array}$ \\
\hline Casa da Criança & $1940-1960$ & $\begin{array}{l}\text { Rotary Clube de } \\
\text { Uberlândia }\end{array}$ & $\begin{array}{l}\text { Externato para filhos } \\
\text { de mulheres pobres } \\
\text { que trabalham fora. }\end{array}$ & - \\
\hline $\begin{array}{l}\text { Casa da Divina } \\
\text { Providencia }\end{array}$ & 1940 & $\begin{array}{l}\text { Sociedade São Vicente de } \\
\text { Paula }\end{array}$ & $\begin{array}{l}\text { Internamento de } \\
\text { meninas órfãs e/ ou } \\
\text { abandonadas }\end{array}$ & $\begin{array}{l}\text { Recolhimento principalmente, } \\
\text { de crianças, filhas de } \\
\text { prostitutas, preparando as para } \\
\text { a prestação de serviços } \\
\text { domésticos. }\end{array}$ \\
\hline $\begin{array}{l}\text { Centro Espírita } \\
\text { Fé esperança e } \\
\text { caridade }\end{array}$ & 1940 & $\begin{array}{l}\text { Centro espírita fé amor e } \\
\text { caridade }\end{array}$ & $\begin{array}{l}\text { Internamento de } \\
\text { doentes mentais }\end{array}$ & - \\
\hline $\begin{array}{ll}\text { Patronato } & \text { de } \\
\text { Menores } & \text { do } \\
\text { Buriti } & \end{array}$ & 1947 & Rotary Clube & $\begin{array}{l}\text { Internamento de } \\
\text { meninos órfãos, } \\
\text { abandonados ou } \\
\text { delinqüientes }\end{array}$ & $\begin{array}{l}\text { Tutela do menor, } \\
\text { desenvolvendo atividade de } \\
\text { horticultura, funilaria, criação } \\
\text { de galinhas, fabrico de telas. }\end{array}$ \\
\hline $\begin{array}{l}\text { Patronato de } \\
\text { menores Rio das } \\
\text { Pedras }\end{array}$ & 1953-1982 & Sociedade Eunice Weaver & $\begin{array}{c}\text { Internamento de } \\
\text { meninos de } 5 \text { a } 17 \\
\text { anos, órfãos ou } \\
\text { abandonados até sua } \\
\text { maioridade. }\end{array}$ & $\begin{array}{l}\text { Fundada sob os auspícios do } \\
\text { programa Nacional de } \\
\text { Proteção do menor. Hoje, é } \\
\text { escola Agrícola. }\end{array}$ \\
\hline Lar Alfredo Júlio & $1950-1970$ & $\begin{array}{l}\text { Centro Espírita Fé } \\
\text { esperança e caridade }\end{array}$ & $\begin{array}{c}\text { Internamento de } \\
\text { meninas órfãs ou } \\
\text { abandonadas até a sua } \\
\text { maioridade. }\end{array}$ & \\
\hline
\end{tabular}

Fonte: Elaborado pelos autores, conforme MACHADO, 1990, p.115

Então, nesse contexto social urbano, a imprensa local dava significado e importância à situação, bem como sinalizava estratégias para a solução do problema. Nesse sentido, o Ginásio Profissional Cristo Rei (1944-1956) foi instituído para assumir o encaminhamento desses menores, numa perspectiva de enfrentamento e de minimização de tal problema:

[...] ser um baluarte de amparo e educação para meninos abandonados [...] ser um baluarte de assistência social para os jovens operários,[...] obra de beneficiência em amparo às crianças abandonadas e necessitadas [...] que abrange uma grande parte da cidade, como também diversos 
distritos do grande municipio de Uberlândia. (INSTITUTO CRISTO REI, A Tribuna, Uberlândia, MG, 1946, p.1)

Nas palavras do Juiz de Menores da Comarca de Uberlândia, Helvécio Rosemburg:

[...] $\mathrm{O}$ índice de criminalidade infantil é aqui bem acentuado. Como medida acauteladora, se construiu um patronato, onde aos menores serão ministrados os primeiros ensinamentos. Daí ingressarão no Ginásio Cristo Rei, recebendo aí o ensino mais aperfeiçoado - curso secundário e profissional. (ROSENBURG, 1947, p.1)

A instituição Cristo Rei, localizada então em região suburbana, representava, nessa época, os interesses dos setores dominantes, que acreditavam no intento de criar condições, por meio do estudo, para uma nova forma de ascensão social. Essas ações tinham como fundamento básico resolver o problema do menor abandonado, sempre em acordo com os principios, particularmente salesianos.

\section{Os salesianos no Brasil}

No Brasil, os salesianos chegaram em 1883, e depararam com um quadro social, político e educacional influenciado pelo positivismo. Segundo Isáu (2005), os salesianos iniciaram suas atividades educativas num momento histórico em que se operavam transformações políticas, sociais e econômicas profundas:

[...] Preferiram às escolas profissionais e agrícolas. Esta preferência não era exclusiva, porque, em algumas casas, o ensino profissional não conseguiu ser aceito. Este atendimento especial dirigia-se aos jovens de origens mais humildes. A grande dificuldade a enfrentar era o preconceito contra o trabalho manual que lembrava a escravidão e movia a população a procurar para seus filhos as escolas secundárias, porquanto essas abriam caminho para os cursos superiores. O curso profissional mais aceito, ou seja, o curso comercial conseguiu prosperar por se assemelhar aos ginásios secundários. (ISAÚ, 2005, p.1)

Nessa condição, o elevado número de pessoas não alfabetizadas impedia a inclusão do Brasil no modelo civilizatório e modernizante. A crença no poder da escola para moralizar, civilizar, modernizar e consolidar a ordem social foi-se difundindo, o que permitia a não justificação do atraso em que se encontrava o Brasil, o qual necessitava, urgentemente, de políticas que organizassem o quadro educacional.

O trabalho salesiano expandiu-se por várias regiões brasileiras, o que permitiu criar verdadeiras inspetorias de ensino de âmbito interno à Congregação em apreço. É notória a importância dessa Congregação para Minas Gerais, ao implantar um sistema de ensino envolvendo crianças, jovens e adultos.

Quadro 02 - Inspetorias salesianas no Brasil

\begin{tabular}{|l|c|l|}
\hline Inspetorias & $\begin{array}{c}\text { Início das } \\
\text { Atividades }\end{array}$ & Unidades da Federação \\
\hline Inspetoria São João Bosco & 1883 & $\begin{array}{l}\text { Distrito Federal, Minas Gerais, Espírito Santo, Rio } \\
\text { de Janeiro, Goiás }\end{array}$ \\
\hline
\end{tabular}




\begin{tabular}{|l|c|l|}
\hline Missão Salesiana de Mato Grosso & 1894 & Mato Grosso, Mato Grosso, Oeste de São Paulo \\
\hline $\begin{array}{l}\text { Inspetoria Salesiana Nossa Senhora } \\
\text { Auxiliadora }\end{array}$ & 1896 & São Paulo \\
\hline Inspetoria Salesiana São Pio X & 1901 & Rio Grande do Sul, Paraná, Santa Catarina \\
\hline $\begin{array}{l}\text { Inspetoria Salesiana São Luis } \\
\text { Gonzaga }\end{array}$ & 1902 & $\begin{array}{l}\text { Alagoas, Bahia, Ceará, Pernambuco, Rio Grande do } \\
\text { Norte, Sergipe }\end{array}$ \\
\hline $\begin{array}{l}\text { Inspetoria Salesiana Missionária da } \\
\text { Amazônia }\end{array}$ & 1921 & Pará, Amazonas, Rondônia \\
\hline
\end{tabular}

Fonte: BITTAR, 2002, p.3.

Após a designação do Padre Lasagna como inspetor no Brasil em 1881, foram criados vários colégios. Entre eles, figuram o Colégio Santa Rosa, em Niterói (1885), o Liceu Coração de Jesus, em São Paulo (1885) e o Liceu de Artes e Ofícios, em Campinas (1897). Em 1900, foi criado o Liceu Salesiano do Salvador. E novos colégios foram acrescidos, como os de Santa Catarina e do Espírito Santo.

Segundo Manacorda (1995, p. 295),

[...] a obra educativa de Dom Bosco, que, iniciada modestamente, impôs, através da Congregação Salesiana, a presença católica no panorama educacional do mundo moderno. Sua obra destaca-se pela reflexão pedagógica, como pela iniciativa da educação popular profissional.

Para Dom Bosco, havia duas formas para a educação da juventude: o disciplinamento e o acompanhamento seriam as molas propulsoras do sistema preventivo.

A "fase de ouro" das Escolas Profissionais Salesianas durou até aproximadamente 1917. [...] "fase de ouro", porque foram premiadas em várias exposições nacionais e internacionais, distinguindo-se, de maneira especial, as do Liceu Coração de Jesus, de São Paulo, do Colégio Salesiano de Santa Rosa, premiadas com várias Medalhas de Ouro e Prata, além de Menções Honrosas. Até o encerramento desta fase (1883 a 1922) era inegável a aceitação das Escolas Profissionais. Elas foram o modelo para as demais escolas profissionais do Brasil. (ISAU, 2005, p.21)

Em Uberlândia, MG, tal modalidade de instituição escolar teve sua representatividade por intermédio do Ginásio Profissional Cristo Rei, a partir de 1944. Com a autorização dada por Dom Alexandre Gonçalves Amaral, Bispo Diocesano de Uberaba, por Decreto de 11 de abril de 1945, oficializou-se a criação da Paróquia Nossa Senhora da Aparecida:

Dom Alexandre Gonçalves Amaral, por mercê de Deus e da Santa Sé Apostólica, Bispo desta Diocese de Uberaba. A todos que o presente decreto virem, saudação, paz e benção em nosso Senhor Jesus Cristo. Fazemos saber que, tendo em vista o grande acréscimo da população e a grande extensão da Paróquia de Nossa Senhora do Carmo de Uberlândia, 
de modo que, sem grave incomodo, não podem os fiéis freqüentar a igreja Matriz, nem o vigário socorrer a todos, é necessário dividi-la, e usando de nossa jurisdição ordinária tendo ouvido o Cabido Diocesano e as partes interessadas, seguindo os dispositivos do Can.142§ 1 e usando das atribuições que nos confere o Can, 1427: Havemos por bem separar, dividir e desmembrar da Paróquia de Nossa Senhora do Carmo de Uberlândia o território abaixo delimitado e, como ele, pelo presente Decreto, erigimos e canonicamente instituímos a PARÓQUIA DE NOSSA SENHORA APARECIDA DE UBERLÂNDIA. (DECRETO DA CRIAÇÃO DA Paróquia Nossa Senhora Aparecida, 1945)

Logo após, foi nomeado, no dia 19 de abril de 1945, o primeiro vigário da Freguesia de Nossa Senhora Aparecida, Pe. João Batista Balke ${ }^{5}$, que tomou posse no dia 22 de abril de 1945.

\section{Educação para menores e o Ginásio Cristo Rei}

A instituição, Ginásio Cristo Rei, foi reconhecida, em Uberlândia, no ano de 1947, quando se iniciou, sob o regime de externato para freqüência masculina, visando ao ensino secundário para crianças pobres, mantendo-se os cursos: profissional, primário, alfabetização e de admissão. No curso profissional, formavam-se tipógrafos, carpinteiros, alfaiates e sapateiros.

Figura 02 - Ginásio Profissional Cristo Rei, anexado à Igreja Nossa Senhora da Aparecida, 1947

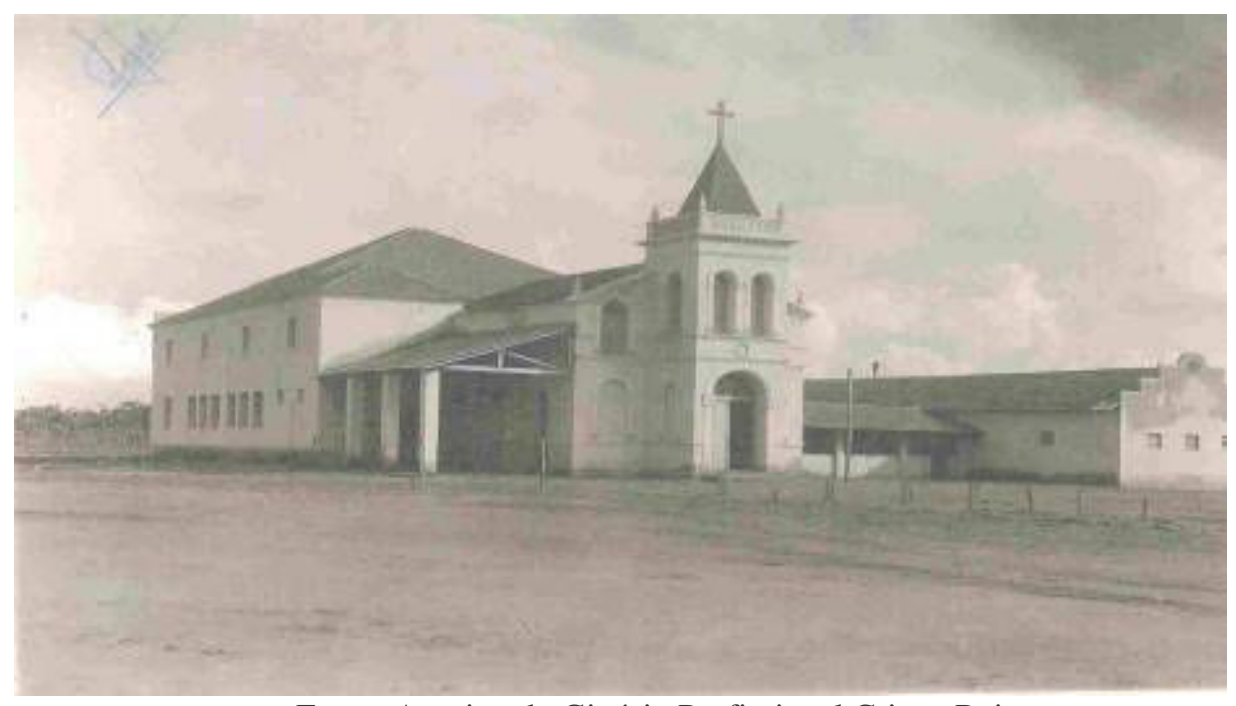

Fonte: Arquivo do Ginásio Profissional Cristo Rei.

Além dessa atividade, a Congregação Salesiana em Uberlândia também administrava a Paróquia Nossa Senhora Aparecida, que inicialmente esteve sob a responsabilidade da Congregação do Preciosíssimo Sangue ${ }^{6}$ sob a orientação do Revmo. Padre Johannes Balke - como se informou anteriormente; a partir de 1948, os salesianos ${ }^{7}$ 
assumiram as atividades pastorais vinculadas à Paróquia em apreço, e o fizeram até 1970, quando também foram encerradas as atividades do Ginásio.

Consta no relatório anual de 1970 que o motivo de seu fechamento foi devido à abertura de vagas no Colégio Estadual de Uberlândia, confirmadas através de uma carta enviada a um ex-aluno do ginásio:

[...] Quando o Estadual começou a lançar número de vagas e foram surgindo os anexos aqui e acolá, adverti ao Pe. Henrique, então diretor, do caos em que nos aproximávamos. [...] exortava o povo e pedia que ajudasse a conservar o Cristo Rei, cujas matrículas iam diminuindo sensivelmente. (PONTES, 1973, p. 1)

Segundo Teodoro (2008),

[...] entre os motivos que levaram ao encerramento das atividades da escola encontra-se como fator principal a perda de apoio político, por parte da Prefeitura Municipal de Uberlândia com a desavença do então Prefeito Renato de Freitas com o atual diretor da escola, padre Henrique Ribeiro de Brito. Pois, segundo este o Prefeito pretendia que a escola aceitasse um grande número de alunos em seu espaço escolar em regime de bolsas parciais em que parte da arrecadação fosse para a Prefeitura, então como a direção do Colégio não aceitou tal condição, o Sr. Prefeito procurou o governador de Minas Gerais e conseguiu a liberação de formação de vários anexos na cidade em que uma boa parte ficou centralizada na região próxima ao Cristo Rei fato este que fez com que diminuísse drasticamente o número de alunos a serem matriculados obrigando a instituição a dar por encerrada suas atividades. (p. 138)

A nosso ver, em decorrência da abertura de vagas oferecida pelo Colégio Estadual e através de seus anexos, bem como da perda do apoio político da Prefeitura Municipal de Uberlândia, o fechamento desse estabelecimento se fez necessário.

Cunha (1989) afirma que o Ginásio Profissional Cristo Rei mesmo estando em pleno funcionamento ao lado da Igreja Nossa Senhora Aparecida desde os princípios do ano de 1944, os padres salesianos persistiam em seus sonhos de construção de uma grande escola para receber um grande número de alunos de diversos níveis sociais, dando continuidade aos fundamentos de Dom Bosco em amparar os menos favorecidos economicamente; visava-se proporcionar uma formação educacional justa e humanitária para todos os cidadãos, fato este que, pelas palavras de Padre Manoel Claro Costa, não ocorreu, pois a escola atendia certa classe que tinha condição de pagar pelas mensalidades.

Nesse sentido, o início do ano de 1952 foi de extrema importância, uma vez que, após ter conseguido a doação de uma grande área, onde hoje se encontra o Campus Santa Mônica da Universidade Federal de Uberlândia, a Congregação Salesiana deu início à construção do novo e moderno Ginásio Cristo Rei.

A planta da escola, elaborada pelo Dr. Luiz Rocha e Silva, foi aprovada, e sua execução entregue ao construtor Sílvio Rugani. As obras tiveram início em 11 de novembro de 1952. No início de janeiro de 1953, o Pe. Augusto Cabral foi transferido para 
Niterói e, para substituí-lo, chegou à Uberlândia, em 06 de fevereiro, o Pe. Zanor Rosa, que dirigiu a obra salesiana até o final de abril, quando a assumiu o Pe. Emílio Miotti.

As obras de construção do colégio continuaram com a colaboração do povo, que realizava mutirões em todos os finais de semana. No mês de junho, iniciou-se a armação das colunas e, em julho, os alicerces da parte superior.

Apesar dos esforços iniciais para a construção do novo prédio do Ginásio (cf. Figura a seguir) no bairro Santa Mônica, que iria funcionar em caráter de internato e externato, acabou sendo vendido para a Universidade Federal de Uberlândia: [...] "nunca funcionou. [...] eles começaram a preparar o terreno e fazer aquela construção [...] era para ser internato" (COSTA, 2008).

Figura 03 - Vista frontal do prédio do Ginásio Profissional Cristo Rei, conhecido na cidade por Mineirão

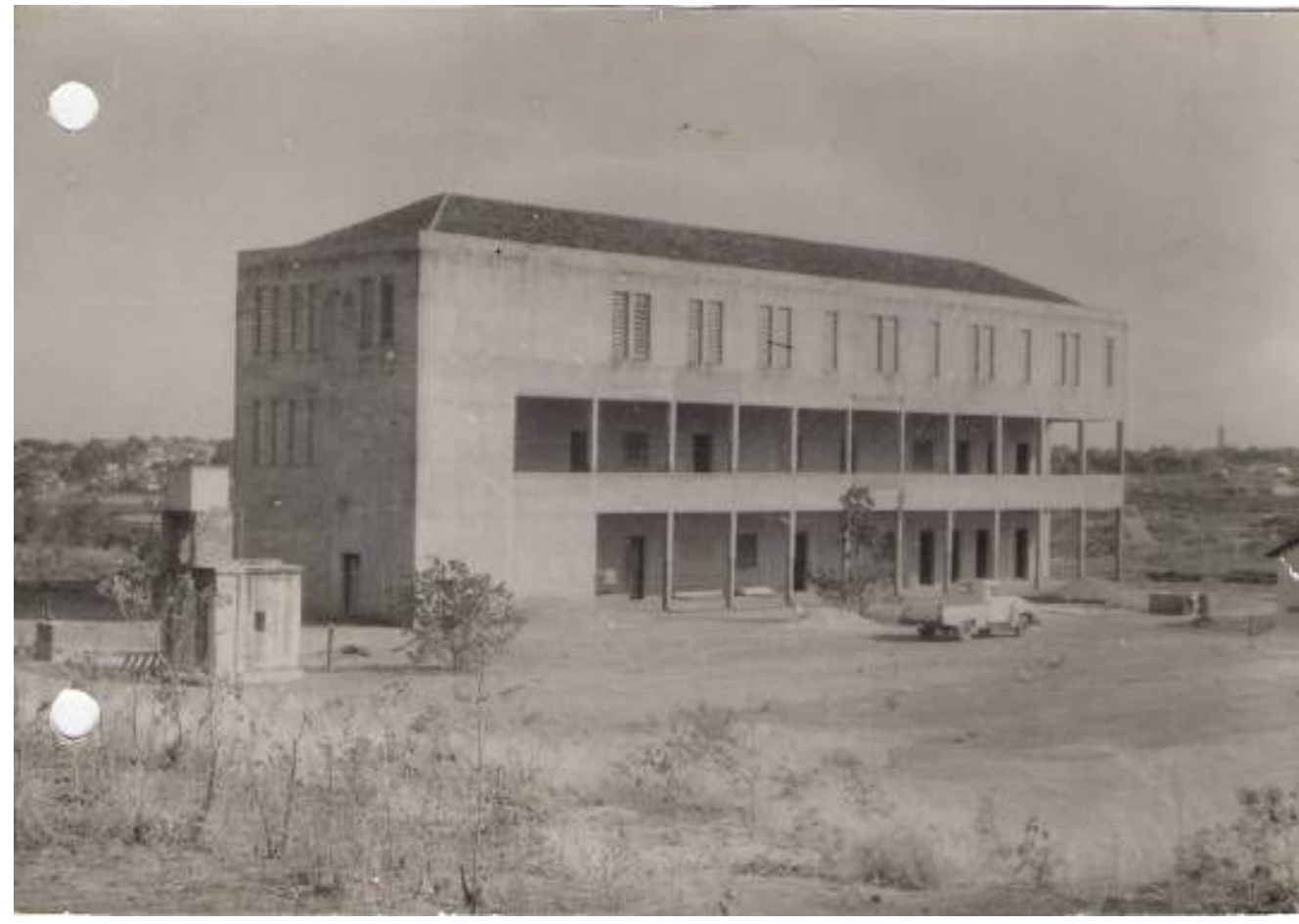

Fonte: Arquivo do Centro de Documentação e Pesquisa em História, UFU

Segundo Cunha (1989),

Pe. Balke tinha um objetivo principal: construir o Instituto Cristo Rei, para instruir os jovens e criar escolas profissionais anexas. No dia 8 de julho de 1945, foi assentada a primeira pedra para a construção do estabelecimento. [...] O ano de 1947 marca a realização do grande sonho

Revista HISTEDBR On-line, Campinas, número especial, p. 266-287, mai.2010 - ISSN: 1676-2584 277 
do dedicado Vigário da Paróquia Nossa Senhora da Aparecida. Inaugurou-se, no dia 15 de janeiro, o Instituto Cristo Rei. [...] o trabalho extraordinário do Pe. Balke foi auxiliado pelos membros da congregação do Preciossissimo Sangue, professores José Siqueira, Nelson Neto Silva e Francisco Cardoso. Coadjuvados pelos professores Pedro Schwindt Filho e Güenter Brune. (CUNHA, 1989, p. 193-194)

A origem dessa escola é algo que parece bastante peculiar, posto que já era um anseio já expresso em um jornal local: “[...] a creação de uma escola profissional em Uberlândia é uma campanha que nós promovemos com o máximo interesse, tal a sua importância social e econômica" (O ESTADO DE GOYAZ, Uberlândia, MG, 1942, p.1). Evidencia-se aqui uma necessidade de instruir crianças e jovens, bem como prepará-los para o trabalho.

Em referência à direção dos salesianos, o relatório do Ginásio Profissional Cristo Rei enviado pelo inspetor Francisco de Palma Souza (1948) ao Sr. Diretor da Divisão do Ensino Secundário, o qual elucida como aconteceu a transferência da Congregação do Preciosíssimo Sangue à Salesiana:

[...] o Ginásio Cristo Rei de Uberlândia foi fundado pelo esforço do sacerdote e exímio educador Padre Johannes Balke, ilustre pároco de Uberlândia, como obra social em amparo à mocidade, em idade escolar e menos favorecida na sorte. Apezar da ingente e abnegada obra realizada pelo emérito sacerdote, não foi possível prosseguir a marcha admirável e idealizada, devido à exigüidade das fontes de renda e auxílio que viessem em apoio e ajuda a tão avultados planos em prol da instrução pública. Contudo, para consolidar as iniciativas tão benéficas e oportunas, os órgãos do Bispado de Uberaba, e hombro a hombro com Administração e Governo Municipais, de Uberlândia, crearam as bases necessárias para organização de um notável Educandário e Estabelecimento, com Internato e externato, com capacidade para 1500 alunos. Ante a [...] grandeza da obra tão vasta, patriótica e palpitante, as referidas entidades acima lançaram seus olhares para a conhecida Congregação de Ensino dos Padres Salesianos de D. Bosco [...] incumbiram-se os padres Salesianos da organização e já apresentavam diretrizes urgentes e necessárias para a imediata execução de alevantado plano (SOUZA, 1948, p. 1).

Ressalte-se que a função desse Educandário seria uma busca pela evangelização da juventude, através da escola, e com o objetivo de fazer veicular a fé católica e de amparar a mocidade, conforme expressa uma reportagem do jornal A Tribuna:

[...] será uma escola "sui generis", como disse o próprio creador. A finalidade principal desta obra será amparar a mocidade desamparada. Administrando-lhe uma sólida instrução moral e cívica, primária e profissional conforme as aptidões e circunstâncias [...]. (ROCHA, 1946, p. 1)

$\mathrm{Na}$ imprensa local, verifica-se um interesse pela constituição dessa escola, que culminou com a iniciativa de particulares, conforme a intenção exposta nesse fragmento de um artigo do jornal O Estado de Goyáz: 
[...] Uberlândia quer uma escola profissional pela iniciativa oficial. Caso isso não se verifique, as nossas classes conservadoras e trabalhistas farão como é de costume da iniciativa particular o seu modo de ação. Porque Uberlândia quando quer uma reivindicação consegue, sacrificando ou empenhando até as cuecas [...]. (O ESTADO DE GOYÁZ, Uberlândia, MG, 1947, p. 3)

Compreende-se, então, que a origem do Ginásio parece inusitada, mas compartilha das crenças e ideais de então: católicos e particulares manifestaram o desejo de se organizarem para controlar os hábitos, as práticas e os comportamentos das crianças das camadas inferiores através dessa unidade de ensino, como confirma a matéria jornalística a seguir:

[...] nesta cidade chave do interior triangulino, que é Uberlândia, o douto e dinâmico padre João Balke criou uma grandiosa e patriótica instituição de amparo aos meninos abandonados ou menos favorecidos. O instituto Cristo Rei ditado pelas circunstâncias locais, enquadra-se perfeitamente nos planos gerais dos problemas que necessitam de uma solução urgente; esta obra pretende favorecer esta solução e ser baluarte de sadio patriotismo. (ROCHA, 1946, p. 1)

Essa escola, no ano de sua abertura oficial $1947^{8}$, contou com a matrícula de 248 alunos no ensino primário, conforme registros no livro de matrícula. Por recomendação do Governo do Estado, matricularam-se no curso de Alfabetização 201 alunos, com a idade de 14 a 30 anos (CUNHA, 1989, p.194). O estabelecimento possuía a capacidade para o funcionamento de sete salas com, no máximo, 37 alunos e, no mínimo, 21 alunos. Atendendo ao curso primário no horário das 07:00 às 11:00 horas; ao curso ginasial, no horário de 12:00 às 17:00 horas; e ao curso profissional, no horário de 19:00 às 23:00 horas.

No início da instalação do colégio, as atividades didáticas foram assumidas, especialmente, por religiosos e católicos, nomeados pelo vigário da Paróquia.

A seguir, um quadro com a relação das matrículas feitas nessa escola, embora incompletas, até o ano de 1956:

Quadro 04 - Matrículas efetuadas entre 1946 e 1956

\begin{tabular}{|c|c|}
\hline ANO & MATRÍCULA \\
\hline 1946 & 215 \\
\hline 1947 & 248 \\
\hline 1950 & 149 \\
\hline 1951 & 216 \\
\hline 1954 & 48 \\
\hline 1956 & 118 \\
\hline
\end{tabular}

Fonte: Ginásio Cristo Rei. Livro de matrícula 
Ao analisar o quadro de matrículas, pode-se observar que houve, no decorrer do período, uma relativa diminuição do número de matrículas. Evidencia-se também a partir do Livro de Matrículas que a instituição recebeu alunos de vários lugares, tais como Tupaciguara, Goiatuba, Morrinhos, Araguari, Canápolis, Prata. Faziam parte do corpo discente da escola, em 1947, 30 alunos internos.

Quanto à finalidade do Ginásio Profissional Cristo Rei, sua origem se define como entidade assistencial, assim expressa por uma correspondência enviada à Diretoria da Divisão do Ensino Secundário, pelo inspetor Francisco de Palma (1948): “[...] atualmente funciona no Ginásio Cristo Rei: o curso primário, curso de admissão, e a assistência social" (p. 1), que tinha como norteamento o sacrifício pela pátria e a produtividade, os quais por meio do trabalho visavam à reeducação de crianças carentes e desajustadas, além de disseminar uma cultura voltada à formação do homem virtuoso, saudável e socialmente organizado.

Conforme o jornal, A Tribuna, a escola oferecia à sua clientela:

Na paróquia N. S. Aparecida de Uberlândia, com aprovação eclesiástica, fundou-se o Instituto Cristo Rei, que manterá as seguintes obras sociais:
A - Patronato "Beato Gaspar" para meninos abandonados
B - Escola primária
C - Escola profissional
D - Curso noturno madureza (curso ginasial) para adultos
E - Restaurante popular
F - Internato para meninos
G - Seminário para formação de religiosos do Preciosíssimo Sangue. (A Tribuna, Uberlândia, MG, 1946, p. 2)

O Ginásio buscou ser uma referência em Uberlândia, em relação à obra social, pois ao fornecer o curso de profissionalização, os padres daquela escola estavam atendendo à grande demanda da sociedade uberlandense, que divisava nessa instituição um instrumento de formação de mão-de-obra. Essa idéia pode ser percebida nos primeiros artigos do Estatuto do Ginásio Profissional Cristo Rei (1947).

Art. 1- Fica fundado na escola Profissional Cristo Rei da Paróquia Nossa Senhora Aparecida de Uberlândia, o curso Ginasial para o ensino de alunos pobres ou filhos de operários.

Art. 2 - O seu objetivo é aperfeiçoar o ensino elementar, lançando uma base sólida para o ensino técnico - profissional, agrícola, industrial e comercial. (ESTATUTO DO GINÁSIO CRISTO REI, 1947).

$\mathrm{O}$ alvo da escola era ministrar o ensino profissional absolutamente gratuito para os alunos pobres, pois de acordo com essa declaração feita pelo Juiz da Comarca de Uberlândia: "Existem outros ginásios, nos quais, pelo padrão de vida elevado em Uberlândia, é inaccessível às classes necessitadas" (ROSENBURG, 1947), mas também 
oferecia vagas para alunos mais abastados, o que é confirmado por essa matéria jornalística:

[...] O Instituto Cristo Rei manterá internato para os alunos de fora, dos quais será cobrado uma taxa mínima de centro e cincoenta cruzeiros, enquanto para os pobres será tudo de graça. Anexo funcionará um patronato para órfãos [...]. (ROCHA, 1946, p. 1)

No entanto, o ex-aluno Manoel fez um relato que contradiz o projeto, conforme prescrito no Estatuto, de ser uma escola para pobres: “[...] a direção do Cristo Rei tinha uma tolerância bastante grande, mas quem estudava era geralmente quem podia pagar mensalidade" (COSTA, 2008).

Em uma correspondência enviada para o Sr. Manoel Crosara, secretário da Câmara Municipal, pelo diretor João Balke, encontra-se a seguinte consideração:

[...] Por questões financeiras do Colégio que se acha endividado devido ao aumento da construção não conseguimos manter o curso profissional gratuito, pois estava o colégio sem recursos, sem verba oficial e a crise impossibilitou aos generosos benfeitores manter o curso gratuito [...]. (BALKE, 1948, p. 2)

O recebimento da subvenção solicitada pelo Pe. Diretor, João Balke, evidencia que a sociedade uberlandense solicitava uma solução concernente às crianças pobres, bem como apoiava a iniciativa dos padres dessa congregação.

Segundo Teodoro (2008),

[...] A escola, embasada no conceito de entidade filantrópica, aproveitava-se da omissão do Estado diante das deficiências educacionais do setor público e tirava vantagens de sua situação de fins não-lucrativos, para receber subvenções e isenções por parte dos órgãos públicos governamentais. (TEODORO, 2008, p. 3)

$\mathrm{Na}$ declaração expedida pelo Juiz de Direito da Comarca de Uberlândia, asseverava-se que:

[...] uma cidade como Uberlândia, de vida caríssima, a mais elevada do Brasil - Central, onde a pobreza prolifera, acentuadamente [...] as obras sociais teem se levantado por obra e graças de arrojados abnegados e denotados padres e cidadãos. Essas obras sociais surgem como elemento mitigador das necessidades das classes pobres. (ROSENBURG, 1947, p.1)

Entende-se, por conseguinte, que o Ginásio Profissional Cristo Rei seria a solução para as camadas baixas da populaçao. Entretanto, deveria ser em um local que atendesse à sua clientela; nesse caso, o melhor local para sua construção foi na periferia da cidade, o que pode ser confirmado na declaração expedida pelo juiz:

[...] O prédio, construído como ficou dito, na grande Vila Operária, na parte mais alta e salubérrima, fora do reboliço do centro comercial, é de construção moderna observada as exigências dos regulamentos de ensino. (ROSENBURG, 1947, p. 2) 
Viu-se que, em relação a outras escolas dessa cidade, que tinham sua localização em regiões centrais, como o caso do Grupo Escolar Júlio Bueno Brandão e do Liceu de Uberlândia, o Ginásio Cristo Rei se localizava na periferia da cidade, no bairro destinado a trabalhadores, a Vila Operária.

Nesse período, a atividade econômica predominante em Uberlândia era o comércio. Porém, havia a intenção de construir um parque industrial; nesse sentido, essa escola profissional poderia representar o começo da realização do projeto, concernente à profissionalização:

[...] A escola profissional de Uberlândia é de vital importância para o nosso sonho de industrialização em massa. Do ponto de vista social a Escola profissional resolverá o problema dos menores abandonados e colocará o nosso trabalhador com um nível intelectual mais elevado [...]. (O ESTADO DE GOYAZ, Uberlândia, MG, 1942, p. 1)

\section{Considerações Finais}

Diante dos documentos analisados, compreendeu-se que a instituição passou por mudança de perspectiva no decorrer de sua existência. Em sua gênese, foi destinada à proteção de crianças de classes inferiores, e constituiu uma forma de intervenção sobre a população infantil, assentado na orientação de "salvar as crianças" da marginalidade, de preservar a paz da cidade e das famílias, em relação aos vândalos, esquadrinhando o espaço da população em geral e dos interesses da elite uberlandense, de dar continuidade a um projeto de ordem e progresso.

Portanto, contribuiu para a realização de um plano maior da elite uberlandense, a higienização social, retirando as crianças abandonadas da rua. Tal intenção está descrita no trecho de um jornal, Diário, num período anterior à criação do Ginásio Profissional Cristo Rei.

Si amparados pelos poderes públicos, organizasse-mos uma sociedade, visando tornar útil a manutenção dos desprotegidos, parece-nos não seria improfícuo qualquer esforço. Um estabelecimento de aprendizagem, por exemplo, resolveria a situação. Quantas intelligencias se perdem por ahi, em virtude da inexistência de uma casa que a ampare, que as estimule e mesmo que as burile, tornando-as, amanhã úteis a sociedade, ao paiz ao próximo. Quanta gente cresce na ambiência que no momento precisamos. Uma plêiade de homens que surge do nada para nada se tornar amanhã, sem profissão, alheios aos bons princípios sociais, vivendo por isso, afastados da sociedade, só mesmo por rara conservação de instincto se torna um homem trabalhador e hordeiro. (NÓS TAMBÉM PRECISAMOS cuidar de nossas crianças pobres, 1936 p. 1-2)

É importante destacar que a sociedade daquela época atribuía à educação um papel fundamental, no sentido de que a escola era co-responsável pela boa formação do caráter. A educação era concebida, segundo Máximo, Costa e Neto (2002), como um fator de preservação social, formando um novo homem. Era necessário que a escola inculcasse normas, princípios e valores nos alunos, permitindo manter a ordem social e a regeneração, 
evitando, assim, o aumento da marginalidade. Foi possível perceber os propósitos dos processos de formação explicitados em coerência com o modelo de aluno que se quis constituir naquele contexto.

Ressalta-se que a intencionalidade dos processos educacionais das crianças pobres, no contexto do Ginásio Profissional Cristo Rei, era condizente com os anseios da sociedade da época - majoritariamente católica. Tal procedimento permitiria um acesso mais fácil às decisões da esfera pública, e abalizaria uma unidade normalizadora, criando uma imagem de sociabilidade.

Desse modo, a Igreja procurava construir um discurso calcado em princípios éticos, associando-os à necessidade de disciplina como forma segura para a manutenção da ordem social, bem como visava contribuir com o crescimento da população produtiva, para assim elevar a quantidade de riqueza para essa cidade com o aumento da mão-de-obra qualificada por meio de sua profissionalização. Havia a preocupação com a formação profissional dos alunos, e a educação destinava-se a um duplo caminho: reeducar crianças pobres e profissionalizá-las.

Em 1950, foi solicitada uma autorização à Diretoria do Ensino Secundário no Rio de Janeiro, uma instância salesiana, para mudar o nome da instituição, que deixou de ser Ginásio Profissional Cristo Rei para Ginásio Cristo Rei.

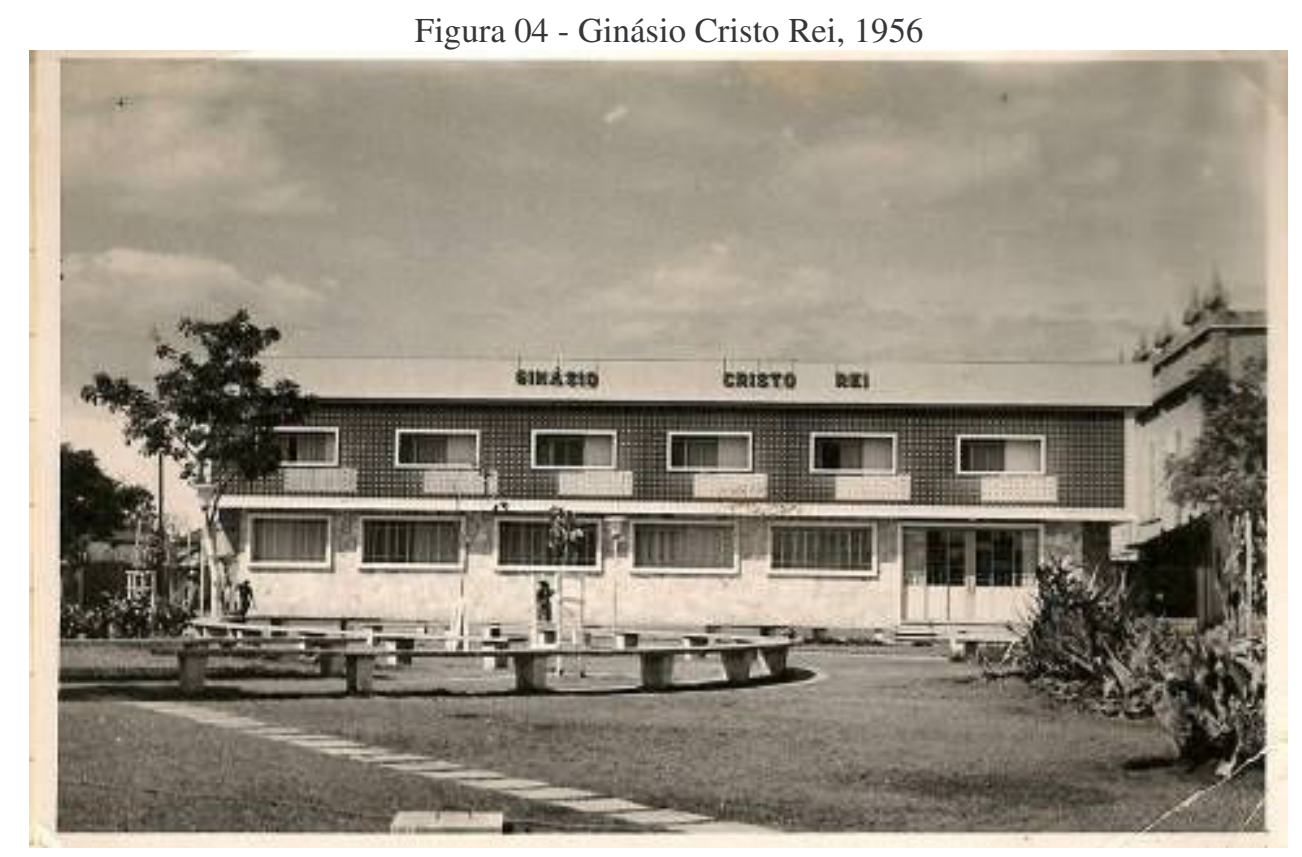

Fonte: acervo particular do ex- aluno, Luiz Alberto

Observa-se desde essa época uma tendência de variação da finalidade da instituição que já caminhava para enfatizar somente o ensino secundário elitista, com conteúdos acadêmicos, atendendo à mudança de interesses da elite uberlandense.

No decorrer de sua existência, houve uma mudança de perspectiva da Congregação Salesiana em relação a uma clientela, atendendo às necessidades educacionais das camadas sociais de Uberlândia mais elitizadas, com um ensino acadêmico. 
Percebe-se que a criação dessa instituição não representou uma saída eficiente para resolver o problema do menor na cidade, uma vez que persistiria o aumento do número de menores, bem como a falta de recursos para manter as oficinas.

O Ginásio Cristo Rei possuía mais que o curso ginasial, como se observou anteriormente, e em seu processo de constituição pluri-institucional foi um estabelecimento que agregou meninos pobres e excluídos. Nesse sentido, contribuiu com o projeto de progresso da cidade, na tentativa de eliminar das áreas públicas os sinais de desordem, traduzidos pela pobreza infantil. Para tanto, foi necessário instruir tais meninos, baseandose nos valores morais e cristãos, e prepará-los para o trabalho, objetivando diminuir o índice de crianças desamparadas em Uberlândia e nas cidades vizinhas, em vista da busca pelo curso ginasial.

\section{Fontes}

A TRIBUNA. Uberlândia, dezembro 1946.

BALKE, João. Correspondência. Uberlândia. 1948.

COSTA, Manoel Claro. Entrevista concedida cedida a Sandra Ferreira de Oliveira no dia 25 de agosto de 2008.

DECRETO DA CRIAÇÃO DA PARÓQUIA NOSSA Senhora Aparecida. Uberlândia, 1945.

FALTA-LHES EDUCAÇÃO. O Repórter, Uberlândia, MG, 1935, p. 2.

GINÁSIO CRISTO REI. Estatuto do Ginásio Cristo Rei, 1947, p. 1.

INSTITUTO CRISTO Rei. A Tribuna. Uberlândia, 1946, p. 1.

NÓS TAMBÉM precisamos cuidar de nossas crianças pobres. Diário. Uberlândia, 1936, p. 1-2.

O ESTADO DE GOYÁZ. Uberlândia, MG, 1942.

O ESTADO DE GOYÁZ, Uberlândia, MG, 1947.

PATRONATO DE MENORES. Uberlândia. O Reporter, Uberlândia, MG, 1943.

PONTES, Agenor Vieira. Correspondência. Inspetoria São João Dom Bosco. Belo Horizonte, 1973.

RELATÓRIO DE VERIFICAÇÃO. Ginásio Profissional Cristo Rei. Uberlândia, 1947

ROSENBURG. Relatório da verificação das Condições do Ginásio Cristo Rei. Histórico do Estabelecimento. Uberlândia, 30 fev. 1947.

ROCHA, José Saldanha. Instituto Cristo Rei. Mocidade Livre, jun. n4, 1946. p.1.

SOUZA, Francisco de Palma. Correspondência à Diretoria da Divisão do Ensino Secundário. Uberlândia, 1948. p.1.

UM CORRECTIVO QUE se impõe. O Reporter. Uberlândia, 1935.p.1 


\section{Referências bibliográficas}

ALVES, Lidiane Aparecida; RIBEIRO FILHO, Vitor. Reestruturação urbana das atividades de comércio e serviços em Uberlândia_MG. VIII Encontro interno, XII Seminário de Iniciação Científica. Uberlândia. 2008. Disponível:<HTTP//www.icufu.org/anaisufu2008/PDF/IC2008-0058.PDF>.

BARRETO, M.A. Dicionário de Ciências Sociais. Rio de Janeiro, Fundação Getúlio Vargas, 1986 (verbete: instituição).

BERMAN. Marshall. Tudo o que é sólido desmancha no ar: a aventura da modernidade. TRD.Carlos Felipe Moisés \& Ane Maria L. IIoriatti. São Paulo: Companhia de Letras, 1986.

BITTAR, Marluce. Política de educação na região sul de Mato Grosso e a influência da congregação salesiana. VI Congresso Internacional of Brazilian Studies Association BRASA, Atlanta, Geórgia/USA, 2002.

CAPRI, Roberto. O Brasil e seus Estados - Minas gerais e seus Municípios: O Triangulo Mineiro. Capri Andrade \& C. Editores, São Paulo, 1916.

CARVALHO, Carlos Henrique de. Delinquência e marginalidade: o problema do menor infrator no espaço urbano de Uberlândia MG. In CARVALHO, C. H.; MOURA, Esmeralda Blanco B. de; ARAUJO, José Carlos S. (org.) A infância na modernidade: entre a educação e o trabalho. Uberlândia, EDUFU, 2007.

CUNHA, Monsenhor Antonio Afonso da; SALAZAR Aparecida Portilho. Nossos pais nos contaram: História da igreja em Uberlândia, 1818-1989. Uberlândia, Universidade Federal de Uberlândia. 1989.

GATTI JÚNIOR, Décio. Reflexões teóricas sobre história das instituições educacionais. Revista Ícone, Uberlândia: Centro Universitário do Triângulo, v. 6, n. 2, 2000.

; PESSANHA, Eurize Caldas. História da Educação, Instituições e Cultura Escolar: conceitos, categorias e materiais históricos. In: GATTI JÚNIOR, Décio e INÁCIO FILHO, Geraldo (orgs.). História da Educação em Perspectiva: ensino, pesquisa, produção e novas investigações. Campinas, SP: Autores Associados; Uberlândia, MG: Editora da Universidade Federal de Uberlândia, 2005.

GIACOMETTO, Rosana; MARTINELI, Antonio e RINALDI, Fábio. A Família Salesiana de D. Bosco. Tradução de Fausto Santa Catarina, Roma: Instiuto salesiano Pio XI, 2000.

ISÁU, Manoel. Educação salesiana no Brasil sudeste de 1880 a 1922. Dimensões e atuação em diversos contextos. Revista HISTEDBR On-line, Campinas, n.18, jun. 2005.

LEFEBVRE, Henri. A revolução urbana. Tradução de Sérgio Martins, Belo Horizonte: Ed. UFMG, 2008.

MACHADO, Maria Clara Tomáz. A disciplinarização da pobreza no espaço urbano burguês: assistência social institucionalizada (Uberlândia 1965-1980 USP). São Paulo, 1990. 
MAGALHÃES, Justino. Um apontamento metodológico sobre a história das instituições educativas. In: SOUSA, C. P. de \& CATANI, D. B. (orgs). Práticas Educativas, Culturas, profissão docente. São Paulo: Escrituras, 1998.

.Contributo para a história das instituições educativas- entre a memória e o arquivo. In FERNANDES, Rogério e MAGALHÃES, Justino (orgs). Para a História do Ensino Liceal em Portugal. Actas dos colóquios do I Centenário da reforma de Jaime Moniz (1894-1895). Universidade do Minho, Braga, 1999.

MANACORDA, M. A. História da educação: da Antigüidade aos nossos dias. 4a . edição. São Paulo: Cortez, 1995.

MÁXIMO, Ciriam Gouveia; COSTA. Márcia Ferreira. GONÇALVES NETO, Wenceslau. Educação, Imprensa e Disciplina. As Escolas Profissionais em Uberlândia, MG (19361950). Cadernos de História da Educação, V1, nº1, 2002.

RAGAZZANI, Dario. Os estudos históricos- educativos e a história da educação. In: SANFELICE José Luiz; SAVIANI, Dermeval; LOMBARDI, José Claudinei (orgs.). História da educação: Perspectivas para um intercâmbio internacional. Campinas, SP: Autores associados: Histebr, 1999.

SILVA, O M. A epopéia ignorada - a pessoa deficiente na história do mundo de ontem e de hoje. São Paulo: Cedas, 1986.

TEIXEIRA Tito. Bandeirantes e Pioneiros do Brasil Central. Uberlândia, MG: Uberlândia Gráfica Editora, 1970.

TEODORO, Julio César Orias. A educação salesiana em Uberlândia. A Gênese do Instituto Teresa Valsé Pantellini (1959-1970). Universidade Federal de Uberlândia (Dissertação), 2008.

Notas:

1 Mestre em Educação pelo Programa de Pós-Graduação em Educação da Universidade Federal de Uberlândia.

2 Doutor em Educação, professor do Programa de Pós-Graduação em Educação da Universidade Federal de Uberlândia.

${ }^{3}$ Denominação da atual área do Triângulo Mineiro, no início de sua colonização.

${ }^{4}$ Uberabinha fora a primeira designação concedida pelo vice-presidente da Província de Minas Gerais, Barão de Camargos, ainda no império, à freguesia de São Pedro de Uberabinha (TEIXEIRA, 1970, p. 41).

${ }^{55}$ Pe. João Batista Balke, natural da Tchecoslováquia, nasceu a 19 de novembro de 1912, veio para o Brasil por intermédio do Revmo. Pe. Júlio Maria, de quem foi auxiliar (CUNHA, 1989, p.192).

${ }^{6}$ Essa congregação foi fundada em 15 de agosto de 1815 por São Gaspar Del Búfalo, sacerdote em Roma, onde se entregou com assiduidade às obras de caridade, assistência e ensino da doutrina cristã, especialmente às crianças pobres. O papa Pio VII conferiu-lhe o encargo de se consagrar às missões, destinadas estas a renovar o fervor dos fiéis. Foi então instituída a congregação de missionários, sob o título de Preciosíssimo Sangue (Dados disponíveis no site: < www.paginaoriente.com/santos/crdb310.htm >. Acesso em 20 de dezembro de 2008). 
${ }^{7}$ A congregação salesiana foi fundada pelo Pe. João Bosco em 08 de dezembro de 1859, em Turim, Itália. Com o nome de Sociedade de São Francisco de Sales - denominação esta que inspira o termo salesiano - a Congregação reunia, à época, seu fundador, Dom Bosco, então com 44 anos de idade, e mais 17 membros; atualmente, a presença salesiana estende-se a 130 países do mundo (GIACOMETTO; MARTINELLI; RINALDI, 2000, p. 51).

${ }^{8}$ No relatório de verificação das condições do Ginásio Cristo Rei em 1947, consta que o padre Johannes Balke construiu, em 1944, na paróquia N. S. Aparecida de Uberlândia, a Escola Profissional Cristo Rei, que era um liceu de artes e ofícios com diversas salas destinadas à aprendizagem do ofício de sapateiro, alfaiate e carpinteiro. Em outras salas, abriu um curso primário e de alfabetização aos adultos. Em 1947, foi aberto o curso de admissão ao ensino secundário (RELATÓRIO DE VERIFICAÇÃO DAS CONDIÇÕES DO Ginásio da Escola Profissional Cristo Rei de Uberlândia, 1947, p.36).

Artigo recebido em: 25/04/2010

Aprovado para publicação em: 31/05/2010 